\title{
Sturge-Weber Syndrome with Port Wine Stain and Bilateral Choroid Plexus Angiomas:A Case Report
}

\author{
KALEEM AHMAD, ${ }^{1}$ SAJID ANSARI, ${ }^{2}$ KANCHAN DHUNGEL, ${ }^{1}$ MUKESH KUMAR GUPTA, ${ }^{1}$ ASHOK RAJ PANT, ${ }^{3}$ RK \\ RAUNIYAR ${ }^{4}$
}

\begin{abstract}
:
Sturge-Weber syndrome is a rarenon-hereditary condition characterized by a hamartomatous vascular proliferation. It is usually unilateral; bilateral involvement is seen only in $15 \%$ cases. We report a case of a 6 month old male child with Sturge-Weber syndrome with its inherent clinical features and typical imaging findings.
\end{abstract}

Keywords: Sturge-Weber Syndrome; Phakomatosis; Neurocutaneous Syndrome; Computed tomography.

\section{Introduction:}

The Sturge-Weber syndrome (SWS) is a rare neurocutaneous disorder which occurs sporadically. It belongs to a group of disorders collectively known as phakomatoses and consists of congenital hamartomatous malformations. ${ }^{1}$ It is characterized by a birth mark called port wine nevi, associated with abnormalities of the brain caused by abnormal blood vessels (angiomas) that occur on the cerebral cortex. ${ }^{2,3}$ These changes are usually unilateral. Bilateral involvement is seen in only $15 \%$ cases. ${ }^{4}$ Port wine nevi are congenital malformations in the dermis of the skin involving venules, capillaries and possibly perivenular nerves. ${ }^{5}$ It is also associated withchoroidal vascular lesions, glaucoma, seizures, neurologic deterioration and eventual neurodevelopmental delay.

\section{Case Report:}

A 6 monthold male child referred to our department for computed tomography (CT) of brain with complaints of repeated tonic colonic seizures. He was born full term followinguneventful birth events and belonged to a poor socio-economic status. There was history of nonconsanguineous marriage of his parents and all the siblings were normal amongst the family. His development milestones

1. Associate Professor, Department of Radiodiagnosis, B.P. Koirala Institute of Health Sciences, Dharan, Nepal.

2. Senior Resident, Department of Radiodiagnosis, B.P. Koirala Institute of Health Sciences, Dharan, Nepal.

3. Junior Resident, Department of Radiodiagnosis, B.P. Koirala Institute of Health Sciences, Dharan, Nepal.

4. Professor, Department of Radiodiagnosis, B.P. Koirala Institute of Health Sciences, Dharan, Nepal.

Correspondence : Dr.Dr. Kaleem Ahmad, Associate Professor, Department of Radiodiagnosis, B.P. Koirala Institute of Health Sciences, Dharan, Nepal. Address: Quarter no. C51.2, BPKIHS, Dharan, Nepal. E mail address: drkalim17@yahoo.co.in were normal and was vaccinated for his age. His physical examination showed nevus flammeusin the midline of the face (Figure 1). The hematologic, biochemical and urinary investigations were normal. Chest and skull radiographs were normal. Abdominal ultrasonography showed no abnormality of the visceralorgans.

Non-contrast computed tomography (CT)of the brain revealed linear hyperdense areasin bilateral temporo-parietal lobes and atrophy of bilateral frontoparietal lobes (Figure $2 a$ and $2 b$ ). Contrast enhanced $\mathrm{CT}$ of brain revealed enhancing multiple leptomeningeal angiomas in bilateral temporo-parietal lobes along with bilateral choroid plexus angiomas (Figure 3a and 3b). The diagnosis of SturgeWeber syndrome was made on the basis of clinical and CT examinations. After neurological consultation,

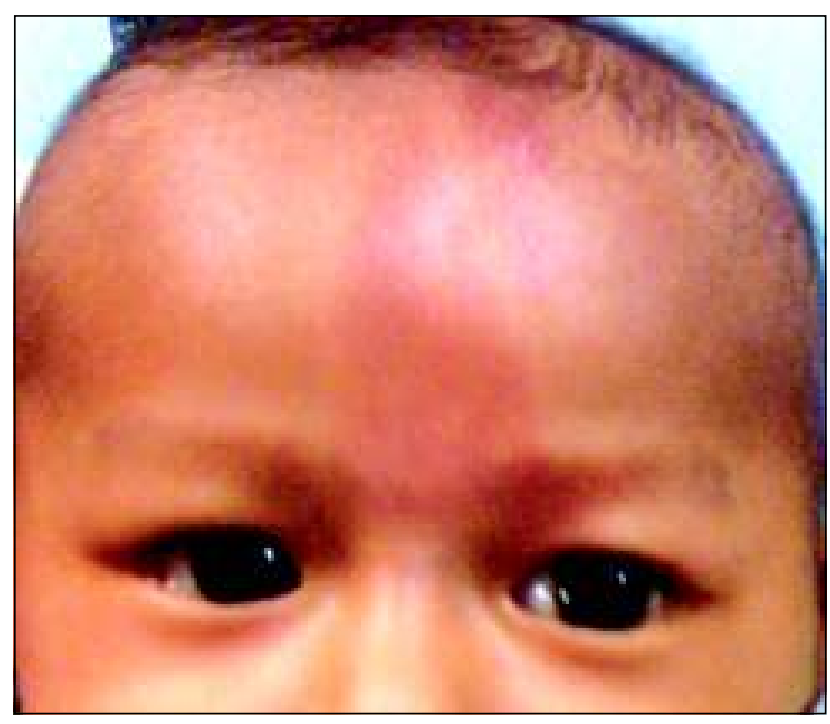

Fig.-1: Photograph of the patient showing nevus flammeus on the forehead in midline. 

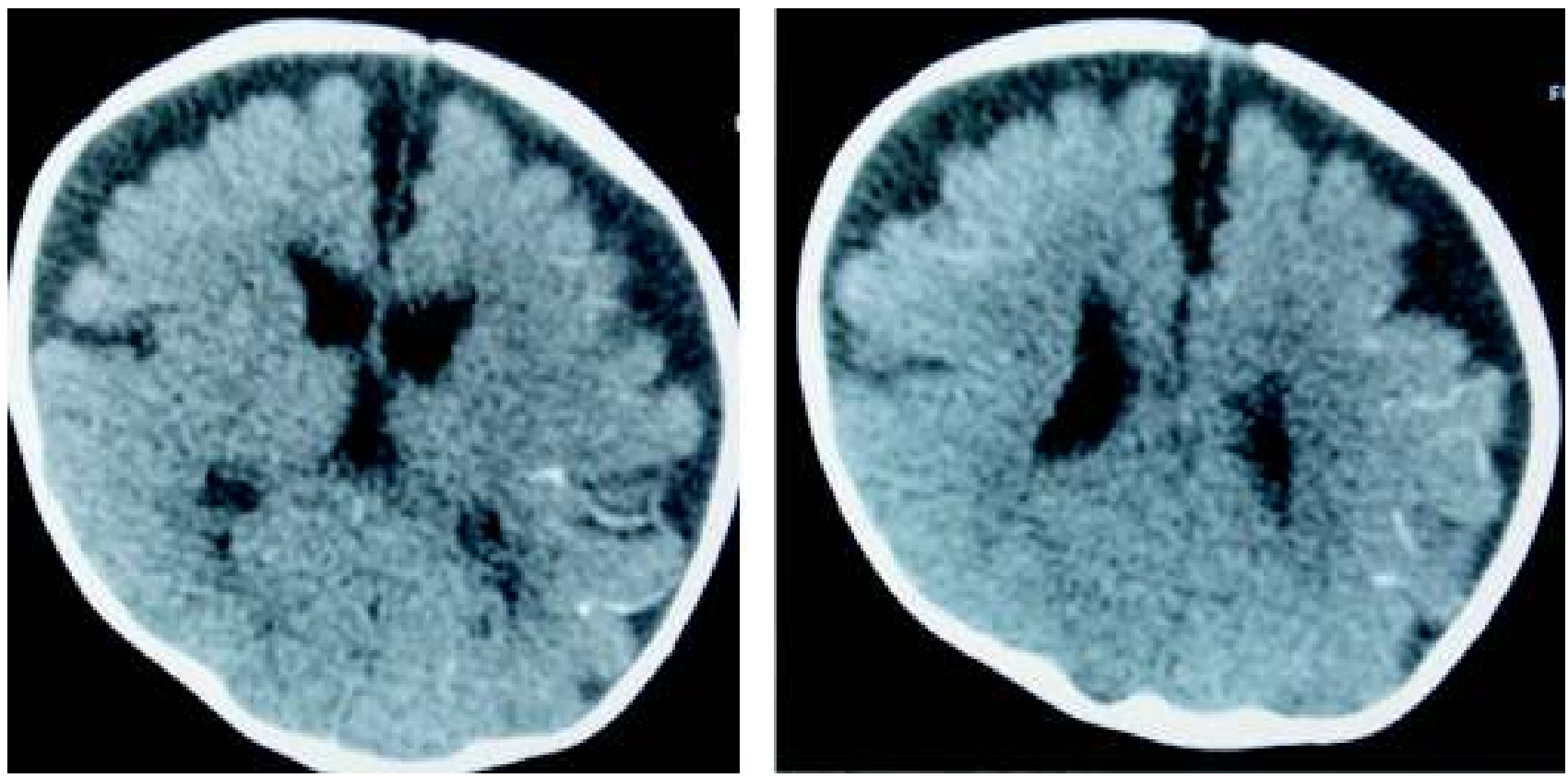

Figure 2a and 2b: Non-contrast CT of the brain showing linear hyperdense areas in bilateral temporo-parietal lobes and atrophy of bilateral frontoparietal lobes.
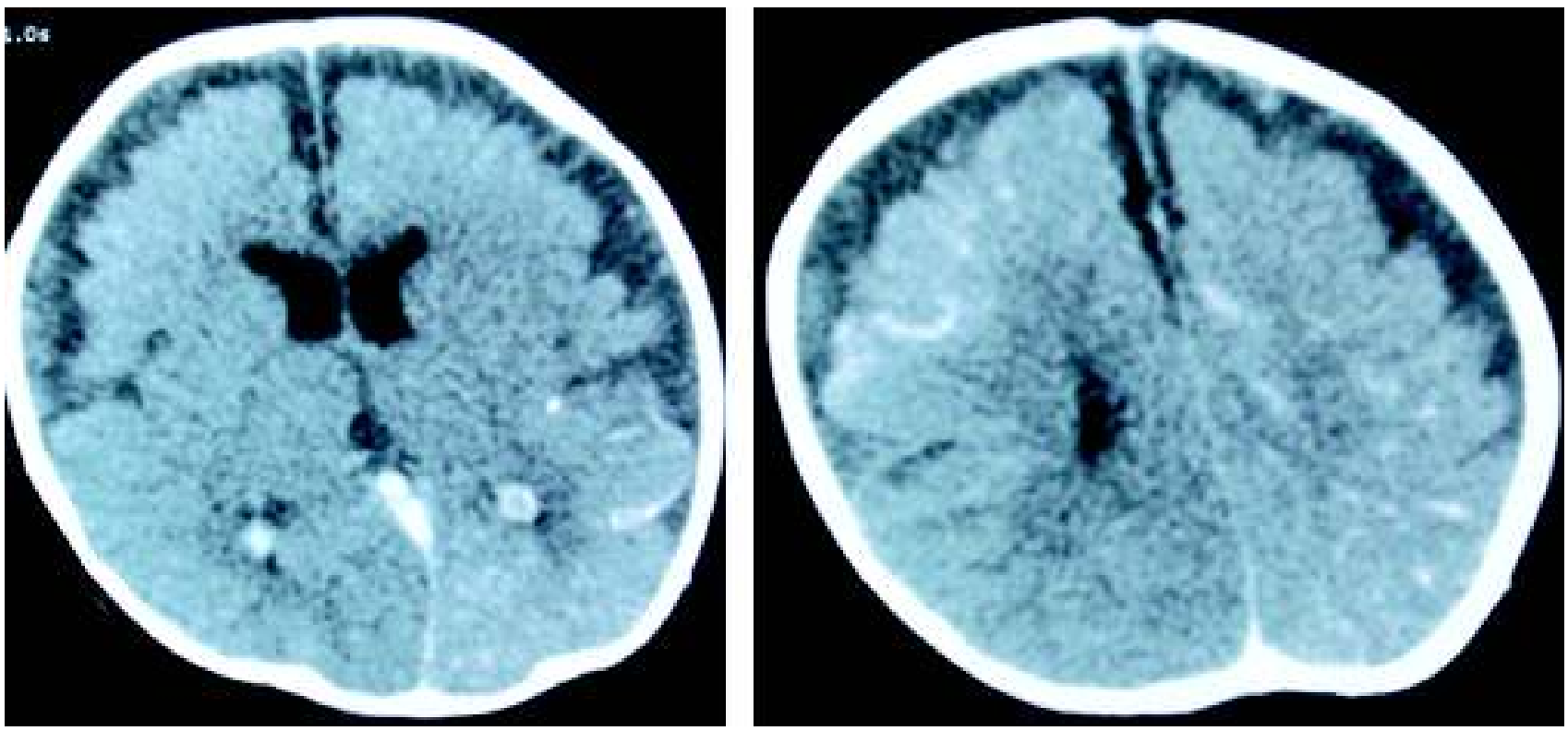

Figure 3a and 3b: Contrast-enhanced CT of brain revealed enhancing multiple leptomeningeal angiomas in bilateral temporo-parietal lobes along with bilateral choroid plexus angiomas.

anticonvulsant drugs were started. But the patient had partial seizures several times. Low amplitude polyphasic spikes and waves activity were noticed on electroencephalography. The frequency of seizures wasreduced after few days and patient was discharged. On follow-up after 5 months, patient was on anticonvulsant drugs and there was no episode of seizure.

\section{Discussion:}

Sturge-Weber Syndrome (SWS) is a congenital but nonhereditary disease. It presents with hamarto-matousmalformations, which results due to the failure of fetal veins to develop normally in the brain, skin and eye. This leads to venous hypertensionand subsequent hypoperfusion of the underlying cortex resulting in chronic cerebral ischemia, atrophy and neurological deterioration. It occurswith equal 
frequency in both sexes, with seizures typically developing in the first year of life ${ }^{6}$ with a frequency of 1:50,000. Neurological deficit is caused by the vascular malformation within the intracranial vessels. ${ }^{7}$ Glaucoma and vascular malformations involving conjunctiva, episclera, choroid and retina ate the ocular manifestations. ${ }^{14}$

Plain radiograph of the skull shows confluent "tram-track" calcifications. CT shows the gyriform calcifications with cortical atrophy,enlarged and enhancing ipsilateral choroid plexus and angiomas. ${ }^{8}$ Cortical calcifications present at birth are reported in $30 \% .{ }^{12} \mathrm{MRI}$ is the best imaging modality for diagnosing SWS while calcifications can be assessed in detail on CT images.

If the onset of seizure is before the age of 2 years, it has a poor prognosis with mental retardation and refractory epilepsy. ${ }^{8}$ SWS has been reported in neonates with seizures in about 75 to $90 \%$ of patients; ${ }^{11}$ even a case of 2 days old baby with SWS and seizure has also been reported in literature. ${ }^{10}$ Portwine stain is common in the pediatric population. According to Enjolras et al, patients with lesions located in the ophthalmic and trigeminal distribution areas are at risk for associated neuro-ocular symptoms. ${ }^{11}$ Most cases with SWS are not life threatening. It is a progressive diseaseassociated with continuous neurological deterioration. ${ }^{9}$

It can be classified in three types;type I- both facial and leptomeningeal angiomas (may have glaucoma), type II facial angiomas alone (may have glaucoma) and type IIIisolated leptomeningealangiomas (usually no glaucoma). ${ }^{16}$

There is a vast list of the differential diagnosis of SWS which includes KlippelTrenaunay Weber syndrome, Rendu-OslerWeber syndrome, Bannayan Riley Ruvalcaba syndrome, Divry Van Bogart syndrome and Cobb syndrome; however the exact differentiation among these entities is not always possible due to overlapping features in many of thesesyndromes. ${ }^{12}$

Management of this syndrome involves both medical and surgical approaches. Medical treatment includes anticonvulsant therapy with prophylactic low dose aspirin to prevent thrombus formation. Port wine stains on the face can be treated by cosmetic surgeons, laser therapy or dermabrasion. ${ }^{15}$

\section{Conclusion:}

SWS is diagnosed and treated on the basis of history, clinical examination and imaging modalities along with the coordination among different fields of medicine, surgery and dentistry. It is difficult to determine the exact etiology of SWS but further research in this field can help in understanding the disease and application of new treatment options.

\section{Conflict of Interest : None}

\section{References:}

1. Rajendran R. Benign and malignant tumors of oral cavity. Shafer's Textbook of Oral Pathology. $6^{\text {th }}$ ed. Noida: Elsevier; 2009:144-5.

2. Thomas-Sohl KA, Vaslov DF, Maria BL.Sturge-Weber syndrome: a review. PediatrNeurol2004;30:303-10.

3. Castilo M.Neuroradiology companion Lippincott W\&W, Philadelphia; 2006:231-233.

4. Boltshauser E, Wilson J, Hoare RD. Sturge-Weber syndrome with bilateral intracranial calcification. J NeurolNeurosurg Psychiatry 1976; 39:429-35.

5. BarskySH, Rosen S, Geer DE, Noe JM.The nature and evaluation of port wine stains: A computer assisted study. J Invest Darmatol1980;74:154-157.

6. BodensteinerJB, Roach ES.Sturge-Weber syndrome: Introduction and overview. Sturge-Weber Foundation, Mt. Freedom, NJ; 1999:1-10.

7. Sturge WA.A case of partialepilepsy apparently due to a lesion of one of the vasomotor centres of the brain. Trans ClinSocLond1879;12:162-167.

8. Osborn A, Salzman K, et al.Diagnostic imaging: Brain Salt Lake City: Amyrsis 2004;1:94-97.

9. Rochkind S, Hoffman HJ, HendrickEB.Sturge Weber Syndrome: natural history and prognosis. J Epilep 1990; 3: 293.

10. Zhuo BY, Lu GJ, Ye ZZ.A case of Sturge Weber syndrome. Zhonghua ErKeZqZhi 2004; 42: 944.

11. Enjolras O, Riche MC, MerlandJJ.Facial port wine stains and Sturge - Weber syndrome. Pediatrics 1985;76(1):48-51.

12. Arif W, Shagufta W, Rizwan A. Sturge Weber syndrome: A Review. Bombay Hospital Journal 2008; 50: 55-58.

13. Muniz AE. Sturge-Weber syndrome presenting as an acute life threatening event. PediatrEmerg Care 2004; 20:610-2.

14. NetoFXP, Junior MAV, XimenesLS, Jacob CCS, Junior AGR, PalhetaCP et al. Clinical features of Sturge-Weber syndrome. Arq. Int. Otorrinolaringol 2008; 12:565-70.

15. Suprabha BS, Baliga M. Total oral rehabilitation in a patient with portwine stains. J Indian 8. SocPedodPrev Dent 2005; 99-102.

16. Roach ES. Neurocutaneous syndromes. PediatrClin North Am 1992; 39:591-620. 